\title{
Valuasi Daya Dukung Fungsi Lindung di Pulau Bintan Propinsi Kepulauan Riau
}

\author{
Agus Bambang Irawan \\ Prodi Teknik Lingkungan UPN 'Veteran’ Yogyakarta \\ Email: microquantum@gmail.com
}

\begin{abstract}
ABSTRAK
Pulau Bintan merupakan salah satu pulau terbesar di Propinsi Kepulauan Riau. Pulau Bintan mempunyai potensi sumber daya alam yang besar dan lokasi sangat strategis terletak di Semenanjung Selatan Malaysia dan menjadi pintu gerbang Selat Malaka. Keunggulan Pulau Bintan ini memicu eksploitasi sumber daya alam secara berlebihan dan pembangunan wilayah yang tidak mengindahkan kelestarian lingkungan. Penelitian ini bertujuan mengevaluasi daya dukung fungsi lindung secara regional maupun sektoral. Metode penelitian yang digunakan adalah penelitian deskriptif dengan melakukan survey lapangan dan institusional serta studi literatur. Hasil penelitian menunjukkan daya dukung fungsi lindung tingkat regional Pulau Bintan berada dalam kondisi sedang. Sebaran daya dukung fungsi lindung di pulau ini tidak merata. Kota Tanjungpinang sudah dalam kondisi rusak, sedangkan Kabupaten Bintan masih dalam kondisi baik. Hasil analisis daya dukung tingkat sektoral beberapa kawasan hutan lindung, hutan mangrove dan terumbu karang sudak mulai rusak. Kerusakan ini disebabkan oleh illegal logging, penambangan bauksit, sedimentasi dan pemanfaatan lahan untuk perkebunan sawit, kebun karet rakyat, permukiman dan pariwisata.
\end{abstract}

Kata Kunci : daya dukung, kawasan lindung, sumber daya alam, illegal logging

\section{PENDAHULUAN}

Pulau Bintan merupakan pulau terbesar di Propinsi Kepulauan Riau yang terdiri atas ratusan pulau besar dan kecil, terbentang di seberang Singapura dan Johor Baru, Malaysia. Letak geografis Pulau Bintan berada diantara Laut Cina Selatan, Selat Malaka dan Selat Karimata. Pulau ini melebar dari Malaka ke Laut Cina Selatan dan posisinya sangat strategis terletak di Semenanjung Selatan Malaysia dan menjadi pintu gerbang Selat Malaka. Pulau Bintan terbagi menjadi 2 wilayah administrasi, yaitu Kota Tanjung Pinang dan Kabupaten Bintan.

Pulau Bintan juga mempunyai potensi sumberdaya alam yang sangat besar, seperti tambang bauksit, perikanan darat maupun laut, rumput laut, terumbu karang, hutan (hutan mangrove dan hutan produksi) dan eksotisme panorama alam yang masih asri dan alami. Keunggulan komparatif ini menjadikan ekonomi utama Pulau Bintan adalah perdagangan antar pulau, pariwisata, pertambangan, perikanan dan kelautan. Dengan letak geografis yang strategis ini dan didukung potensi alam yang sangat besar, Pulau Bintan dimungkinkan untuk menjadi salah satu pusat pertumbuhan ekonomi bagi Republik Indonesia dimasa depan.

Aktivitas ekonomi pembangunan tersebut secara langsung maupun tidak langsung menyebabkan terjadinya penurunan daya dukung wilayah di Pulau Bintan pada masa akan datang yang sulit untuk dihindari. Hal ini didukung dengan laju angka pertumbuhan penduduk Pulau Bintan rata-rata 4,5\% 
tahun. Jumlah penduduk Pulau Bintan pada tahun 2009 adalah 359.783 jiwa (BPS KEPRI, 2010) sehingga pada tahun 2033 jumlah penduduk Pulau Bintan diperkirakan mencapai 1.012.429 jiwa. Jumlah penduduk yang bertambah cukup tajam ini meningkatkan kebutuhan akan lahan untuk memenuhi kebutuhan hidup. Hal ini memicu alih fungsi lahan pada kawasan lindung menjadi lahan produksi secara besar-besaran. Kawasan lindung adalah wilayah yang ditetapkan dengan fungsi utama melindungi kelestarian lingkungan hidup yang mencakup sumberdaya alam dan buatan. Kawasan budidaya adalah wilayah yang ditetapkan dengan fungsi utama untuk dibudidayakan atas dasar kondisi dan potensi sumberdaya alam, sumberdaya manusia dan sumberdaya buatan (Muta'ali, 2003). Kasus alih fungsi lahan terjadi pada perubahan kawasan hutan lindung bagi pembangunan Bandar Sri Bintan dan pengembangan kawasan wisata terpadu (Lagoi) di Pulau Bintan. Alih fungsi lahan ini berdampak pada penurunan fungsi beberapa jenis ekosistem seperti hutan lindung, mangrove, pantai, daerah aliran sungai dan terumbu karang. Fenomena ini selanjutnya akan menimbulkan degradasi lingkungan, bencana alam (banjir dan kekeringan) serta konflik sosial yang dapat mengancam keberlangsungan hidup manusia dan makhluk hidup lainnya di Pulau Bintan.

Memperhatikan hal tersebut, serta menghindari terjadinya penurunan atau "overshoot" daya dukung dan daya tampung wilayah, kajian daya dukung fungsi lindung wilayah Pulau Bintan perlu dilakukan. Tujuan penelitian ini adalah mengevaluasi daya dukung fungsi lindung secara regional maupun sektoral untuk dapat menjadi dasar bagi perencanaan pemanfaatan sumber daya alam dan pembangunan wilayah di Pulau Bintan.

\section{METODE PENELITIAN}

Metodologi penelitian ini menggunakan metode penelitian deskriptif. Data-data yang digunakan berupa data primer maupun data sekunder. Data primer diperoleh melalui survey langsung ke lapangan, sedangkan data sekunder diperoleh dari instansi-instansi pemerintah maupun studi literatur.

Kajian daya dukung fungsi lindung Pulau Bintan dibagi menjadi 2 bagian, yaitu daya dukung fungsi lindung tingkat regional dan tingkat sektoral. Pada tingkat regional penentuan daya dukung fungsi lindung digunakan rumus (Muta'ali, 2012) di bawah ini: 


$$
D D L=\frac{\sum L g l 1 \cdot \alpha 1+L g l 2 \cdot \alpha 2+L g l 3 \cdot \alpha 3+\cdots+L g l n \cdot \alpha n}{L W}
$$

Keterangan:

$$
\begin{array}{ll}
\text { DDL } & =\text { daya dukung fungsi lindung } \\
\operatorname{Lgl}_{n} & =\text { luas guna lahan jenis } \mathrm{n}(\mathrm{ha}) \\
\alpha_{\mathrm{n}} & =\text { koefisien lindung untuk guna lahan } \mathrm{n} \\
\mathrm{LW} & =\text { luasan wilayah (ha) }
\end{array}
$$

Daya dukung fungsi lindung (DDL), memiliki kisaran nilai antara 0 (minimal) sampai 1 (maksimal). Nilai mendekati angka1, semakin baik fungsi lindung yang ada dalam wilayah tersebut, demikian pula sebaliknya, apabila mendekati angka 0, fungsi lindung semakin buruk atau lebih berfungsi sebagai kawasan budidaya. Adapun tingkat kualitas daya dukung fungsi lindung adalah sebagai berikut:

- Sangat rusak jika nilai DDL $0-0,20$

○ Rusak jika nilai DDL 0,20 - 0,40

○ Sedang jika nilai DDL 0,40 - 0, 60

○ Baik jika nilai DDL $0,60-0,80$

- Sangat Baik jika nilai DDL $0,80-1$

Pada kajian daya dukung fungsi lindung tingkat sektoral dipilih kawasan hutan lindung, hutan mangrove dan terumbu karang. Pemilihan kawasan tersebut didasarkan pada proporsi luasan ketiga daerah tersebut mendominasi Pulau Bintan dibandingkan kawasan lindung lainnya. Ketiga kawasan tersebut dikaji kondisi riil saat ini, khususnya tingkat kelestarian kawasan lindung terhadap alih fungsi lahan dan pemanfaatannya untuk lahan produksi. Pada kawasan terumbu karang ditetapkan standar kualitas terumbu karang sebagai berikut:

○ buruk apabila mempunyai tutupan karang hidup sebesar $0-25 \%$

○ sedang apabila tutupan karang hidup $25-50 \%$

○ bagus apabila tutupan karang hidup $50-75 \%$

○ sangat bagus apabila mempunyai tutupan karang hidup $75-100 \%$ (Sudiono, 2008) 


\section{HASIL PENELITIAN DAN PEMBAHASAN}

\section{Kondisi Sumber Daya Alam}

Pulau Bintan mempunyai potensi sumber daya alam yang cukup melimpah, baik sumber daya alam hayati maupun non hayati. Sumber daya alam hayati Pulau Bintan meliputi sumber daya hutan, sumber daya perikanan dan kelautan, sedangkan sumber daya alam non hayati meliputi sumber daya mineral dan tambang.

Pulau Bintan memiliki potensi perikanan yang potensial untuk dikembangkan baik perikanan tangkap maupun perikanan budidaya. Potensi perikanan ini apabila digarap secara optimal akan memberikan pemasukan yang besar bagi penduduk Pulau Bintan. Potensi perikanan tangkap di Pulau Bintan lebih besar dibandingkan dengan perikanan budidaya. Hal ini selain dilihat dari kateristik daerah kepulauan, juga dilihat dari produksi yang dihasilkan setiap tahunnya. Terdapat perbedaan kecenderungan produksi perikanan tangkap dengan perikanan budidaya. Perikanan tangkap mengalami kenaikan dari 23.432,00 ton (tahun 2006) menjadi 25.758,60 ton (tahun 2008). Sedangkan perikanan budidaya mengalami penurunan yang sangat drastis, yaitu dari 18.955,91 ton menjadi 456,00 ton. Untuk lebih jelasnya mengenai produksi perikanan di Pulau Bintan dapat dilihat pada tabel 1 berikut:

Tabel 1. Jumlah Produksi Perikanan Tangkap dan Budidaya di Pulau Bintan Tahun 2008 (Ton)

\begin{tabular}{|c|c|r|r|r|r|r|r|}
\hline \multirow{2}{*}{ No } & \multirow{2}{*}{$\begin{array}{c}\text { Kabupaten } \\
\text { / Kota }\end{array}$} & \multicolumn{3}{|c|}{ Perikanan Tangkap } & \multicolumn{3}{c|}{ Perikanan Budidaya } \\
\cline { 3 - 8 } & \multicolumn{1}{|c|}{$\mathbf{2 0 0 6}$} & $\mathbf{2 0 0 7}$ & \multicolumn{1}{c|}{$\mathbf{2 0 0 8}$} & \multicolumn{1}{c|}{$\mathbf{2 0 0 6}$} & \multicolumn{1}{c|}{$\mathbf{2 0 0 7}$} & \multicolumn{2}{c|}{$\mathbf{2 0 0 8}$} \\
\hline 1 & Kab. Bintan & $20.932,00$ & $20.932,00$ & $21.978,60$ & $14.239,41$ & 512,00 & 344,00 \\
\hline 2 & Kota Tanjungpinang & $2.500,00$ & $3.600,00$ & $3.780,00$ & $4.716,50$ & 407,00 & 112,00 \\
\hline & Jumlah & $\mathbf{2 3 . 4 3 2 , 0 0}$ & $\mathbf{2 4 . 5 3 2 , 0 0}$ & $\mathbf{2 5 . 7 5 8 , 6 0}$ & $\mathbf{1 8 . 9 5 5 , 9 1}$ & $\mathbf{9 1 9 , 0 0}$ & $\mathbf{4 5 6 , 0 0}$ \\
\hline
\end{tabular}

Sumber : BPS Provinsi Kepulauan Riau, 2008

Pulau Bintan mempunyai hasil-hasil laut seperti ikan, terumbu karang, padang lamun, rumput laut dan lain-lain sangat melimpah. Potensi sumber daya kelautan dan perikanan tersebut merupakan potensi ekonomi yang strategis dengan nilai jual yang tinggi. Secara khusus potensi sumber daya pesisir dan pulau-pulau kecil juga merupakan kawasan wisata yang memberikan kontribusi penerimaan daerah yang cukup besar. 
Keberadaan terumbu karang terletak di pesisir timur dan selatan Pulau Bintan. Kabupaten Bintan merupakan salah satu kabupaten di Provinsi Kepulauan Riau yang terdiri dari 240 pulau-pulau kecil serta memiliki sumberdaya pesisir dan laut yang sangat potensial. Luas ekosistem terumbu karang Kabupaten Bintan ini meliputi 43,5\% dari luas ekosistem terumbu karang di Provinsi Kepulauan Riau. Jenis terumbu karang di Pulau Bintan adalah Terumbu karang penghalang (barrier reefs). Terumbu karang ini terletak pada jarak yang relatif jauh dari pulau, sekitar 0,52 km ke arah laut lepas dengan dibatasi oleh perairan berkedalaman hingga 75 meter. Terumbu karang ini terkadang membentuk lagoon (kolam air) atau celah perairan yang lebarnya mencapai puluhan kilometer. Umumnya karang penghalang tumbuh di sekitar pulau sangat besar atau benua dan membentuk gugusan pulau karang yang terputus-putus. Ekosistem terumbu karang di Kabupaten Bintan telah sejak lama dimanfaatkan untuk berbagai kegiatan ekonomi, seperti lokasi penangkapan ikan dan wisata bahari dengan melibatkan banyak pemangku kepentingan (stakeholders). Pemanfaatan ekosistem terumbu karang sebagai lokasi penangkapan ikan dan wisata bahari ini telah berdampak positif terhadap ekonomi (Adriman dkk, 2012).

Sebaran terumbu karang di perairan Pulau Bintan tersebut sekarang kondisinya dijumpai 14 famili dan 78 jenis karang ditemukan dengan kondisi buruk sampai sedang. Hal ini akibat penambangan bauksit dan pasir di wilayah pesisir, kelebihan tangkap (over fishing), penggunaan metode penangkapan ikan yang merusak (bom dan setrum), dan lain-lain. Rumput laut yang bisa dijumpai di Pulau Bintan ini meliputi kelompok alga merah (Achanthophora muscoides. gif), alga hijau (Boergesiana forbessii. gif) dan alga coklat (Ctoseria sp). Kedalamannya mulai dari garis pasang surut terendah sampai sekitar 40 meter. Kabupaten Bintan memiliki kawasan rumput laut terbesar di Provinsi Kepulauan Riau. Estimasi luasan ekosistem kelautan per kabupaten/kota secara rinci termuat dalam tabel berikut:

Tabel 2. Estimasi Luasan Ekosistem Kelautan di Pulau Bintan Tahun 2008

\begin{tabular}{|c|l|r|r|r|r|}
\hline No & \multicolumn{1}{|c|}{ Kabupaten/ Kota } & \multicolumn{1}{c|}{$\begin{array}{c}\text { Terumbu } \\
\text { Karang } \\
\text { (Ha) }\end{array}$} & $\begin{array}{c}\text { Padang } \\
\text { Lamun } \\
\text { (Ha) }\end{array}$ & \multicolumn{1}{c|}{$\begin{array}{c}\text { Hutan } \\
\text { Mangrove } \\
\text { (Ha) }\end{array}$} & \multicolumn{1}{c|}{$\begin{array}{c}\text { Rumput } \\
\text { Laut (Ha) }\end{array}$} \\
\hline 1 & Kab. Bintan & $9,085.33$ & $2,918.36$ & $8,895.87$ & $18,507.82$ \\
\hline 2 & Kota Tanjungpinang & 300 & 150 & 730 & Tad \\
\hline & \multicolumn{1}{|c|}{ Jumlah } & $\mathbf{9 , 3 8 5 . 3 3}$ & $\mathbf{3 , 0 6 8 . 3 6}$ & $\mathbf{9 , 6 2 5 , 8 7}$ & $\mathbf{1 8 , 5 0 7 . 8 2}$ \\
\hline
\end{tabular}

Sumber: RTRW Provinsi Kepulauan Riau Tahun 2008

Ket : Tad (tidak diperoleh data) 
Kawasan hutan yang terdapat di Pulau Bintan pada awalnya terdiri dari hutan lindung, hutan produksi terbatas, hutan mangrove dan hutan konversi dengan luas total 109.701 ha Kawasan hutan yang terdapat di Pulau Bintan banyak mengalami perubahan. SK Menteri Kehutanan Nomor: 955/Kpts-II/1992 merubah fungsi hutan produksi seluas 12.950 ha dan hutan konversi seluas 21.750 ha yang terletak di kelompok hutan Sei Jago, Sungai Ekang, Sungai Anculai, Sungai Bintan, Sungai Kangboi dan Sungai Kawal Pulau Bintan menjadi kawasan hutan lindung yang selanjutnya dikenal dengan nama kawasan Catchment Area. Tipe kawasan hutan yang ada di Pulau Bintan saat ini dapat dikelompokkan menjadi Hutan Lindung (4.355 ha), Catchment Area (37.000 ha), Hutan Produksi Terbatas (21.250 ha), Hutan konversi (40.250 ha), Hutan Mangrove (9.146 ha), dengan total jumlah 112.001 ha (RPJP KEPRI, 2006).

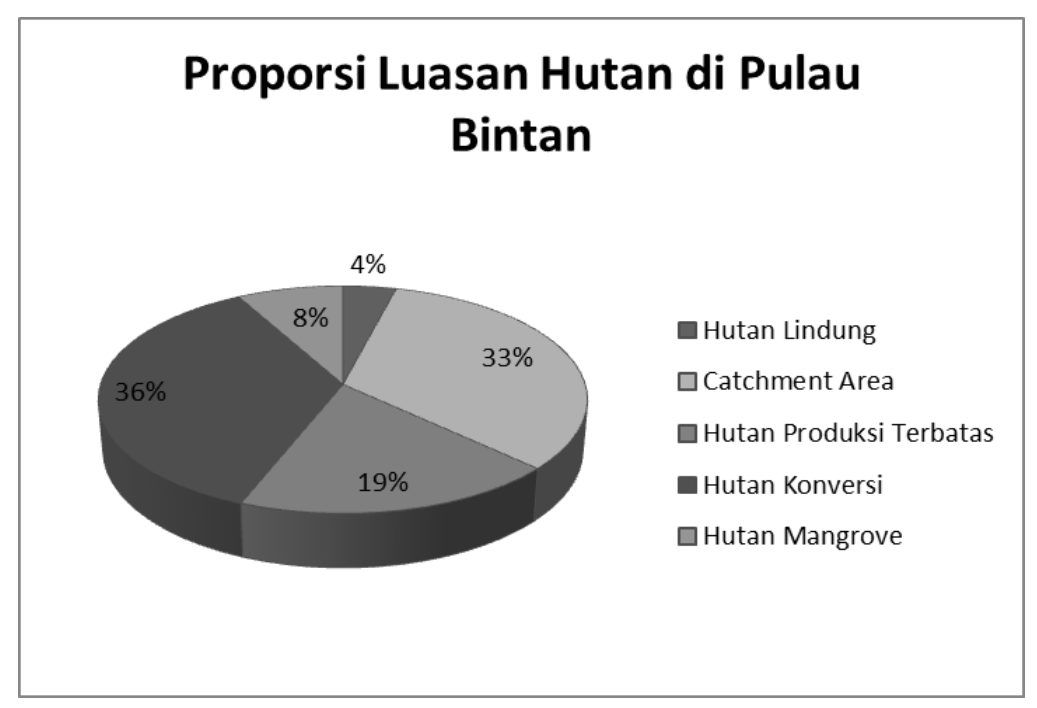

Gambar 1. Proporsi luasan tiap tipe hutan di Pulau Bintan (hasil analisis)

Daerah Pulau Bintan mempunyai bahan galian utama bauksit, dan selain bahan galian utama terdapat pula bahan galian lain, baik yang telah ditambang/diusahakan maupun yang belum ditambang. Bahan galian tersebut di antaranya andesit, granit, pasir darat dan lempung. Nilai potensi bahan galian di Pulau Bintan adalah bauksit sebesar 15.000.000 ton, granit 681,8 ha dan pasir darat 574,96 ha.

Tabel 3. Sebaran Potensi Sumber Daya Mineral di Pulau Bintan

\begin{tabular}{|c|l|l|}
\hline No & $\begin{array}{c}\text { Jenis bahan } \\
\text { galian }\end{array}$ & \multicolumn{1}{c|}{ Lokasi Sebaran Potensi Sumber Daya Mineral } \\
\hline 1 & Bauksit & $\begin{array}{l}\text { Kec. Bintan Timur, Teluk Bintan, Teluk Sebong, Gunung Kijang (Kabupaten } \\
\text { Bintan); Pulau Dompak dan Senggarang (Kota.Tanjungpinang) }\end{array}$ \\
\hline 2 & Granit & Kec.Bintan Timur dan Bintan Utara (Kab.Bintan) \\
\hline 3 & Pasir kwarsa & Kec.Bintan Timur dan Bintan Utara, Gunung Kijang, Teluk Bintan (Kab.Bintan) \\
\hline
\end{tabular}

Sumber: RTRW Provinsi Kepulauan Riau, 2008 


\section{Analisis Daya Dukung Fungsi Lindung Tingkat Regional}

Analisis daya dukung fungsi lindung di Pulau Bintan dibahas perwilayah administrasi, yaitu Kota Tanjungpinang dan Kabupaten Bintan, kemudian sebarannya dianalisis perkecamatan.

Hasil perhitungan dan analisis data-data daya dukung fungsi lindung di Kota Tanjungpinang memperlihatkan nilai 0,2901 (Tabel 4). Nilai ini sudah mendekati angka nol, sehingga Kota Tanjungpinang dalam kondisi rusak. Ini artinya kondisi wilayah sudah tidak bisa menjaga kelestarian lingkungan hidup yang mencakup sumberdaya alam dan buatan. Kerusakan lingkungan di Kota Tanjungpinang bisa dipahami karena perkembangan kota yang pesat dengan maraknya permukiman dan perkantoran serta bekas kawasan tambang bauksit yang belum direklamasi. Lahanlahan bekas tambang bauksit dibiarkan begitu saja sehingga muncul lahan terbuka yang tidak teratur dan kurang terawat.

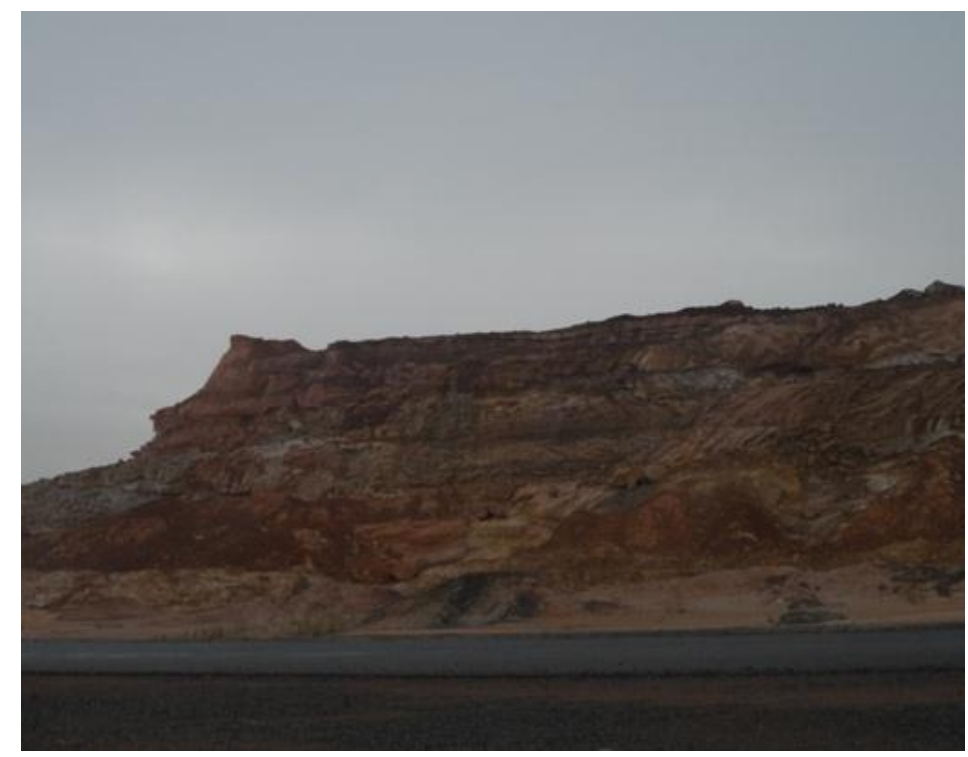

Gambar 2. Lahan bekas tambang bauksit di Kota Tanjungpinang

Jika dilihat hasil perhitungan dan analisis data untuk daya dukung fungsi lindung Kabupaten Bintan, memperlihatkan nilai daya dukung fungsi lindung (DDL) sebesar 0,722643731 (Tabel 5). Angka ini lebih dekat ke angka 1, sehingga peruntukan wilayah Kabupaten Bintan untuk menjaga kelestarian lingkungan hidup berada dalam kondisi baik. 
Tabel 4. Daya Dukung Fungsi Lindung Kota Tanjung Pinang Tahun 2011

\begin{tabular}{|c|c|c|c|c|c|}
\hline No & Penggunaan Tanah & Luas (Ha) & $\begin{array}{c}\text { Luas Wilayah } \\
(\%)\end{array}$ & $\alpha$ & $\mathrm{L}^{*} \alpha(\mathbf{H a})$ \\
\hline 1 & Badan Air & 404,84 & 2,78 & 1 & 404,844 \\
\hline 2 & Cagar Budaya & 6,03 & 0,04 & 1 & 6,033544 \\
\hline 3 & Fasilitas Ibadah & 13,37 & 0,09 & 0,18 & 2,407269 \\
\hline 4 & Fasilitas Kesehatan & 11,03 & 0,08 & 0,18 & 1,985832 \\
\hline 5 & Fasilitas Pendidikan & 38,11 & 0,26 & 0,18 & 6,85891 \\
\hline 6 & Fasilitas Umum & 12,41 & 0,09 & 0,18 & 2,23295 \\
\hline 7 & Hutan & 73,30 & 0,50 & 1 & 73,30006 \\
\hline 8 & Industri & 47,63 & 0,33 & 0 & 0 \\
\hline 9 & Kebun & 70,73 & 0,48 & 0 & 33,95117 \\
\hline 10 & Kebun Campuran & $2.995,57$ & 20,54 & 0,21 & 629,0694 \\
\hline 11 & Kolong & 76,89 & 0,53 & 0,98 & 75,35195 \\
\hline 12 & Komplek Militer & 21,27 & 0,15 & 0,18 & 3,828088 \\
\hline 13 & Mangrove & $1.501,86$ & 10,30 & 0,64 & 961,1918 \\
\hline 14 & Perdagangan dan Jasa & 198,31 & 1,36 & 0,18 & 35,69525 \\
\hline 15 & Perikanan & 3,40 & 0,02 & 0,98 & 3,328492 \\
\hline 16 & Perkantoran & 31,66 & 0,22 & 0,18 & 5,698275 \\
\hline 17 & Permukiman & $1.753,57$ & 12,02 & 0,18 & 315,642 \\
\hline 18 & Pertambangan Terbuka & $1.448,35$ & 9,93 & 0 & 0 \\
\hline 19 & Rawa & 153,29 & 1,05 & 0,98 & 150,227 \\
\hline 20 & Ruang Terbuka Hijau & 9,54 & 0,07 & 0,98 & 9,344959 \\
\hline 21 & Semak & $4.818,25$ & 33,04 & 0,28 & 1349,11 \\
\hline 22 & $\begin{array}{l}\text { Tanah Terbuka } \\
\text { Sementara }\end{array}$ & 798,31 & 5,47 & 0,18 & 143,6963 \\
\hline 23 & Tegalan/Ladang & 80,28 & 0,55 & 0,21 & 16,85983 \\
\hline 24 & TPU & 15,85 & 0,11 & 0,01 & 0,158463 \\
\hline & Total & $14.583,85$ & 100,00 & & 4230,816 \\
\hline \multicolumn{5}{|r|}{ DDL } & 0,29010 \\
\hline
\end{tabular}

Sumber : Badan Pertanahan Nasional RI (Tahun 2011) dan hasil analisis

Kondisi ini didukung masih banyak dijumpai kawasan lindung, berupa hutan lindung, hutan mangrove, catchment area, terumbu karang, dan kolong. Kawasan lindung ini sangat berperan menjaga kelestarian lingkungan alam maupun buatan, baik untuk wilayah Kabupaten Bintan maupun untuk Kota Tanjungpinang. Keberadaan kawasan lindung berfungsi menjaga ketersediaan sumber daya air dan melindungi wilayah Pulau Bintan dari bencana alam, berupa banjir, kekeringan, perubahan iklim, tanah longsor, erosi dan abrasi tebing sungai serta abrasi air laut. 
Tabel 5. Daya Dukung Fungsi Lindung Kabupaten Bintan Tahun 2010

\begin{tabular}{|c|c|c|c|c|c|}
\hline No. & Jenis Penggunaan Tanah & Luas $\left(\mathbf{m}^{2}\right)$ & Luas (Ha) & $\alpha$ & $\mathbf{L}^{*} \alpha\left(\mathbf{m}^{2}\right)$ \\
\hline 1 & Danau & $3.935 .031,17$ & 393,50 & 0,98 & 3856330,547 \\
\hline 2 & Hutan & $727.762 .240,79$ & $72.776,22$ & 1 & 727762240,8 \\
\hline 3 & Perkampungan & $23.680 .880,57$ & $2.368,09$ & 0,18 & 4262558,503 \\
\hline 4 & Perkebunan & $69.929 .114,27$ & $6.992,91$ & 0,48 & 33565974,85 \\
\hline 5 & Pertambangan & $26.408 .908,91$ & $2.640,89$ & 0 & 0 \\
\hline 6 & $\begin{array}{l}\text { Pertanian Tanah Kering } \\
\text { Semusim }\end{array}$ & $372.263 .445,08$ & $37.226,34$ & 0,46 & 171241184,7 \\
\hline 7 & Semak & $18.343 .447,82$ & $1.834,34$ & 0,28 & 5136165,39 \\
\hline 8 & Sungai & $4.821 .212,48$ & 482,12 & 0,98 & 4724788,23 \\
\hline 9 & Tanah Terbuka & $69.190 .598,20$ & $6.919,06$ & 0,01 & 691905,982 \\
\hline & Total & 1.316.334.879,29 & $131.633,49$ & & 951.241.149 \\
\hline \multicolumn{5}{|r|}{ DDL } & 0,722643731 \\
\hline
\end{tabular}

Sumber : Badan Pertanahan Nasional RI (Tahun 2010) dan hasil analisis

Keberadaan kawasan lindung secara umum masih dalam kondisi baik, namun untuk beberapa kasus di tingkat lokal dan sektoral telah terjadi kerusakan lingkungan. Kerusakan lingkungan di kawasan lindung lebih disebabkan oleh kegiatan perambahan hutan, penambangan liar, pembukaan kebun kelapa sawit dan karet, serta aktivitas industri yang membuang limbahnya ke lingkungan sekitar. Akibat kerusakan lingkungan di kawasan lindung ini mengakibatkan semakin menurunnya daya dukung wilayah Pulau Bintan untuk menjaga kelestarian lingkungan alam maupun buatan di tingkat lokal.

Pada tabel 7 ditunjukkan sebaran daya dukung fungsi lindung untuk setiap kecamatan di Pulau Bintan. Wilayah dengan daya dukung fungsi lindung sangat parah terjadi di Kecamatan Tanjungpinang Barat. Rusaknya kondisi wilayah ini, dimulai dengan adanya alih fungsi hutan menjadi Pelabuhan Bandar Sri Bintan. Keberadaan pelabuhan ini secara langsung maupun tidak langsung telah memicu aktivitas pembangunan perkantoran, perdagangan, hotel dan permukiman. Alih fungsi lahan ini telah mengakibatkan hutan yang pada mulanya berperan sebagai kawasan lindung menjadi kawasan budidaya, akibatnya di Kecamatan Tanjungpinang Barat sangat sulit untuk menampung aktivitas pembangunan yang berkelanjutan. Wilayah di Kota Tanjungpinang lainnya juga berada dalam kondisi rusak. 
Tabel 7. Sebaran Nilai Daya Dukung Fungsi Lindung (DDL) di Pulau Bintan

\begin{tabular}{|l|r|c|}
\hline \multicolumn{1}{|c|}{ Kecamatan } & DDL & Kondisi \\
\hline Bintan Pesisir & 0,545947632 & sedang \\
\hline Bintan Timur & 0,845335868 & sangat baik \\
\hline Bintan Utara & 0,40446328 & sedang \\
\hline Gunung Kijang & 0,755116633 & baik \\
\hline Mantang & 0,744164975 & baik \\
\hline Seri Kuala Lobam & 0,587257623 & sedang \\
\hline Tambelan & 0,70755221 & baik \\
\hline Teluk Bintan & 0,810946888 & sangat baik \\
\hline Teluk Sebong & 0,737944056 & baik \\
\hline Toapaya & 0,82746486 & sangat baik \\
\hline Bukit Bestari & 0,266345399 & rusak \\
\hline Tanjungpinang Barat & 0,085954217 & sangat rusak \\
\hline Tanjungpinang Kota & 0,282256293 & rusak \\
\hline Tanjungpinang Timur & 0,283755275 & rusak \\
\hline Pulau Bintan & $\mathbf{0 , 5 6 3 1 7 8 9 4 4}$ & sedang \\
\hline
\end{tabular}

Sumber : Hasil analisis perhitungan

Kondisi ini sangat berkebalikan untuk wilayah kecamatan di Kabupaten Bintan. Rata-rata kondisi wilayah di Kabupaten Bintan berada dalam kondisi baik. Wilayah dengan kondisi sedang berada di Kecamatan Bintan Utara, Bintan Pesisir dan Seri Kuala Lobam, sedangkan kecamatan dengan kondisi sangat baik bisa dijumpai di Kecamatan Bintan Timur, Teluk Bintan dan Toapaya.

Jika dilihat Pulau Dompak sebagai kawasan strategis dan Pusat Pemerintahan Propinsi Kepulauan Riau dari Peta Daya Dukung Fungsi Lindung di atas, menunjukkan dalam kondisi rusak. Ini diperlihatkan bahwa Pulau Dompak berada di Kecamatan Bukit Bestari dengan nilai daya dukung fungsi lindungnya adalah 0,266345399. Kondisi ini menunjukan daerah ini berada dalam kondisi rusak. Kerusakan ini disebabkan wilayah Pulau Dompak merupakan bekas kawasan tambang bauksit dan wilayah ini banyak dibangun perkantoran untuk Pusat Pemerintahan Propinsi Kepulauan Riau. 


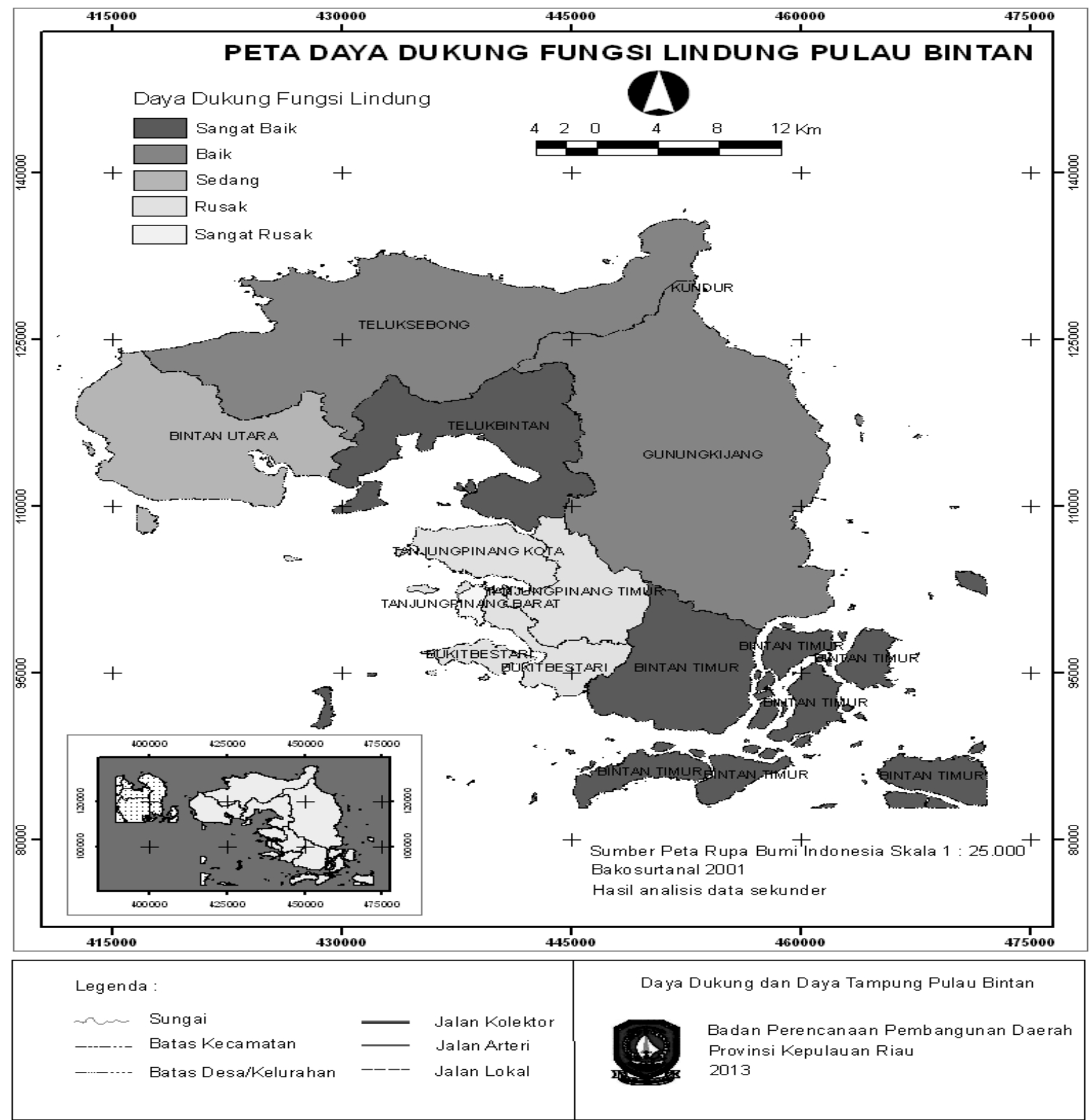

Gambar 3. Peta Daya Dukung Fungsi Lindung di Pulau Bintan

\section{Analisis Daya Dukung Fungsi Lindung Tingkat Sektoral}

Analisis daya dukung fungsi lindung tingkat sektoral ini dibahas melihat aspek kawasan lindung yang berada di Pulau Bintan. Kawasan lindung tersebut berupa hutan lindung, hutan mangrove dan terumbu karang. Ketiga kawasan lindung ini sangat berperan menjaga kelestarian lingkungan dalam mendukung maupun menampung aktivitas pembangunan berkelanjutan di Pulau Bintan. 


\section{Hutan Lindung}

Fungsi utama hutan lindung adalah penyuplai air secara merata di wilayah Pulau Bintan. Keberadaan hutan lindung ini harus tetap terjaga kelestariannya sepanjang masa dan tidak boleh dikonversi untuk peruntukan lain. Kondisi hutan lindung di Pulau Bintan berada dalam keadaan masih baik sampai dengan rusak parah. Hutan lindung yang masih dalam kondisi baik adalah Hutan Lindung Gunung Bintan Kecil dan Gunung Bintan Besar serta Bukit Kucing. Hutan Lindung Gunung Bintan Kecil dan Gunung Bintan Besar berfungsi sebagai hutan penyangga Catchmet Area Pulau Bintan, sedangkan Hutan Lindung Bukit Kucing berperan untuk melindungi sumber air kebutuhan PLN, dan Taman Wisata Kota Tanjung Pinang.

Hutan lindung yang sudah mulai rusak adalah Hutan Lindung Sungai Pulai, Hutan Lindung Bukit Lengkuas, Hutan Lindung Gunung Kijang dan Hutan Lindung Sei Jago. Hutan Lindung Sungai Pulai memiliki permasalahan berupa pemanfaatan lahan untuk perkebunan sawit, kebun karet rakyat, permukiman dalam kawasan yaitu Kampung Suka Damai, Tirto Mulyo, Pondok Pesantren, dan akses jalan yang tinggi.

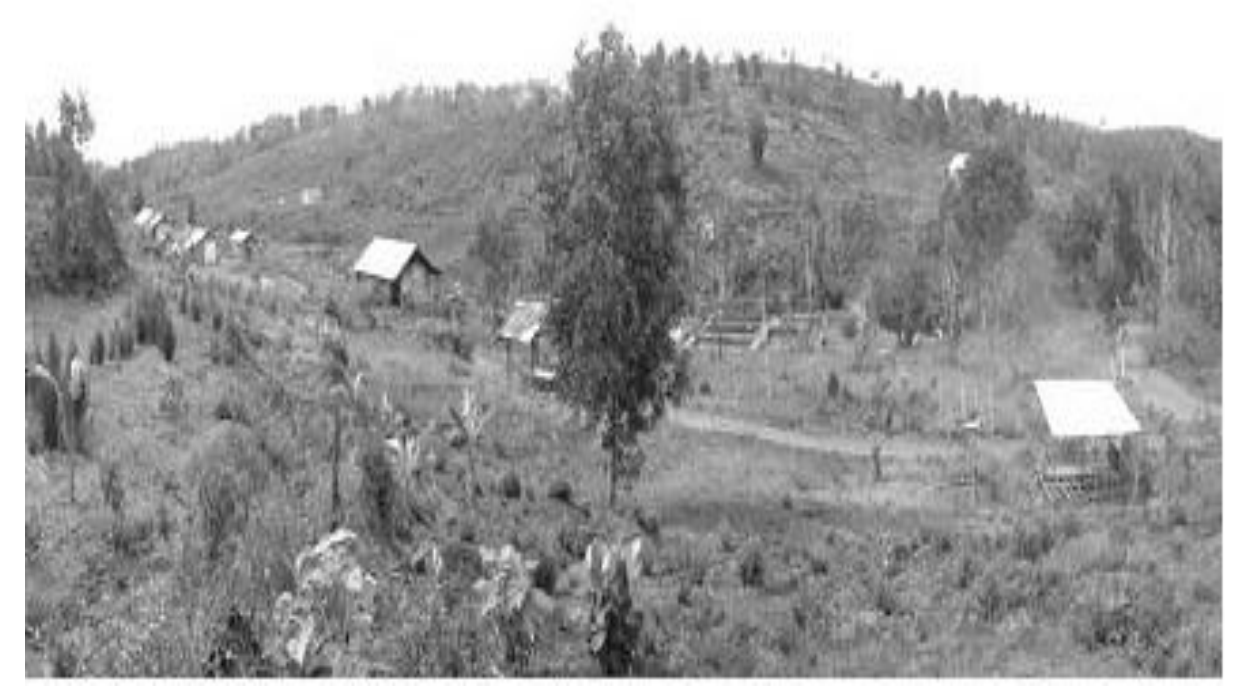

Gambar 4. Foto permukiman penduduk di hutan lindung Sungai Pulai

Sedangkan Hutan lindung Gunung Kijang memiliki permasalahan berupa adanya perkampungan, industri granit, akses jalan yang tinggi, illegal logging. Hutan Lindung Gunung Kijang dan Hutan Lindung Sungai Lengkuas dapat diperkirakan separo luas arealnya telah terambah. 
Berdasarkan kondisi hutan lindung Pulau Bintan di atas, maka secara umum kondisi hutan lindung berada dalam kondisi sedang. Ini artinya hutan lindung masih bisa menampung aktivitas pembangunan di Pulau Bintan, meskipun sebagian hutan telah rusak. Kerusakan hutan lindung masih bisa diatasi dengan adanya penegakan hukum secara formal dan pendekatan sosial kemasyarakatan. Pendekatan hukum secara formal bisa ditegakkan kepada semua pihak baik aparat pemerintah (eksekutif maupun legislatif) dan pihak swasta yaitu pengusaha yang berusaha menyuap aparatur negara. Pendekatan sosial kemasyarakatan ditujukan kepada rakyat kecil yang berusaha menggantungkan hidupnya dari hutan. Mereka bisa didampingi untuk dilakukan pembinaan agar dalam memanfaatan sumber daya hutan menerapkan kaidah-kaidah konservasi dan pembangunan berkelanjutan.

\section{Hutan Mangrove}

Hutan mangrove di Pulau Bintan memiliki beberapa fungsi yaitu fungsi fisik, biologik dan ekonomi. Hutan Mangrove berfungsi secara fisik untuk menjaga stabilitas pantai, melindungi pantai dari abrasi air laut dan erosi tebing sungai, mengolah limbah dari aktivitas manusia di daratan dan "tempat parkir" air hujan. Secara biologis hutan mangrove menjadi tempat tumbuh larvae udang, kerang, ikan, tempat bersarang beraneka jenis burung serta biota lainnya. Sedangkan secara ekonomi hutan mangrove berfungsi sebagai sumber perekonomian masyarakat dalam hal pemanfaatan kayu dan pengembangan perikanan.

Kondisi hutan mangrove di Pulau Bintan secara umum masih dalam kondisi sedang - baik, namun beberapa lokasi telah mengalami kerusakan yang serius. Pemanfaatan kayu mangrove untuk industri arang atau dapur arang telah lama berkembang dan diusahakan oleh masyarakat dan terus meningkat. Ijin pengusahaan panglong arang tahun 2004 berjumlah 10 ijin pengusahaan panglong arang dengan target produksi $4.980 \mathrm{~m}^{3}$, tahun 2005 ada 11 ijin dengan target produksi $6.180 \mathrm{~m}^{3}$, dan pada tahun 2006 meningkat menjadi 20 ijin pengusahaan arang dan target produksi lebih dari $6.380 \mathrm{~m}^{3}$. Luas yang terbatas dengan target produksi yang tinggi akan menyebabkan laju kerusakan mangrove yang cepat.

Kegiatan tambak dengan membuka hutan mangrove belum banyak dilakukan di Kabupatan Bintan. Pada umumnya masyarakat lebih sering menggunakan keramba dalam melakukan budidaya ikan. Meskipun demikian, aktivitas pembukaan hutan mangrove untuk dijadikan lokasi tambak sudah mulai dilakukan. Hal ini terlihat dikawasan Sungai Tiram, Desa Penaga, Teluk Bintan. Kegiatan 
pembalakan juga terjadi di kawasan hutan mangrove di Kabupaten Bintan. Pembalakan ini terjadi dengan cara masyarakat membagi kawasan mangrove menjadi tanah kapling. Tanah tersebut kemudian dialihfungsikan menjadi kawasan perkebunan maupun kawasan pemukiman. Alih fungsi kawasan mangrove menjadi kawasan perkebunan (pisang dan nanas) dapat ditemukan di Sungai Tiram, sedangkan alih fungsi kawasan mangrove menjadi kawasan pemukinan dapat ditemukan di Selat Bintan.

Permasalahan lain yang terdapat di kawasan mangrove berupa pemanfaatan untuk kegiatan tambang bauksit. Aktivitas tambang bouksit untuk pengolahan, penampungan limbah tailing, aktivitas pengangkutan turut andil terjadi kerusakan mangrove. Kegiatan tambang di Kabupaten Bintan secara umum merugikan kawasan hutan mangrove. Kawasan tambang yang memiliki lokasi di atas kawasan hutan mangrove memberikan dampak negatif dengan pencemaran air yang dipergunakanuntuk proses tailing. Akibat pencemaran tersebut, hutan mangrove yang berada di sekitar lokasi tailing menjadi layu, kering dan kemudian mati. Hal ini seperti yang terjadi di kawasan tambang Teluk Bintan.

Selain itu penimbunan kawasan mangrove untuk lokasi pengangkutan bahan hasil tambang juga sangat merugikan karena merusak hutan mangrove dan mengakibatkan hutan mangrove yang juga digunakan sebagai habitat satwa liar menjadi terfragmentasi. Habitat yang terganggu kan menyebabkan adanya reduksi populasi terhadap satwa liar terutama mamalia besar yang membutuhkan daerah elajah yang luas, untuk kawasan hutan mangrove di Kabupaten Bintan adalah jenis primata. Terjadinya fragmentasi juga menjadi pemicu adanya kegiatan perburuan terhadap satwa liar karena akses menjadi lebih mudah. Hal ini terbukti di daerah Tanjung Mamboi, pegawai tambang biasa berburu satwa liar untuk dimakan.

Konsep pengelolaan hutan mangrove adalah menyeimbangkan fungsi fisik, biologik dan ekonomi. Pemanfaatan kayu dari hutan mangrove perlu diimbangi dengan upaya revegetasi/reboisasi agar populasi tanaman mangrove tetap terjaga. Pada daerah-daerah aliran sungai dan tepi laut sebaiknya tanaman mangrove tetap dibiarkan hidup untuk menjaga stabilitas fisik lingkungan dari erosi dan abrasi. Kegiatan reklamasi terhadap area bekas tambang juga harus dilakukan. Usaha ini bisa dilakukan dengan adanya pembuatan lokasi persemaian oleh perusahaan-perusahaan tambang bauksit. 


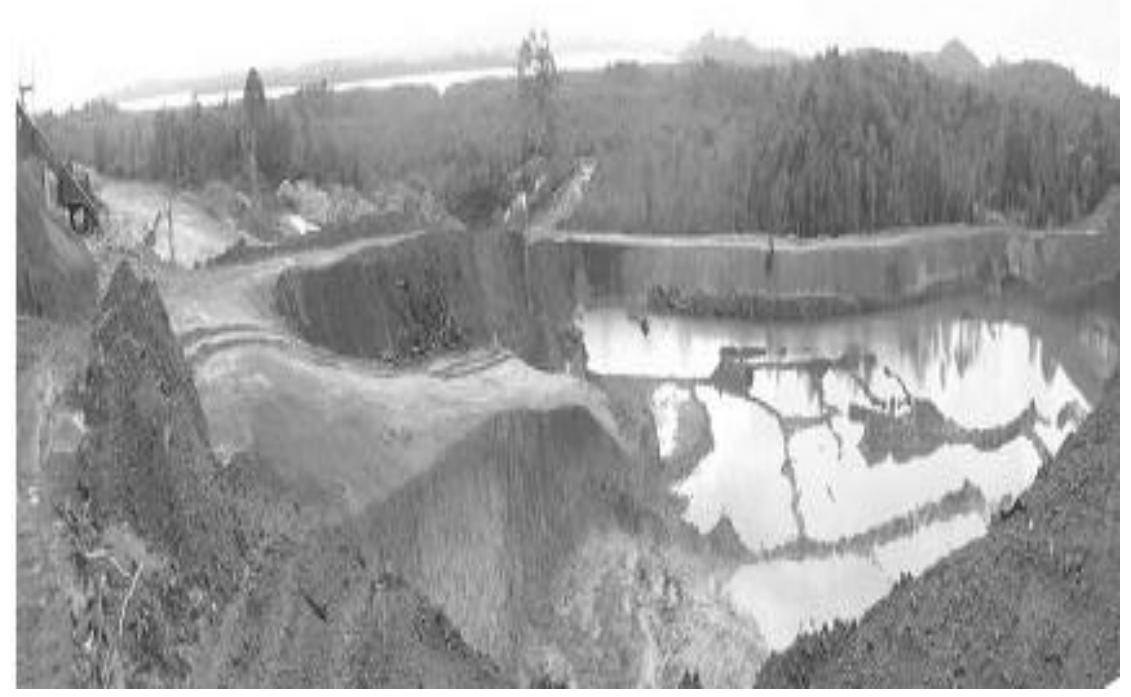

Gambar 5. Foto pemanfaatan kawasan mangrove sebagai tempat pengolahan bauksit dan penampungan limbah tailing

\section{Terumbu Karang}

Ekosistem terumbu karang sebagai salah satu ekosistem utama pesisir dan laut di Pulau Bintan memiliki nilai ekologis dan ekonomis yang tinggi. Selain berperan sebagai pelindung pantai dari hempasan ombak dan arus kuat, terumbu karang juga mempunyai nilai ekologis antara lain sebagai habitat, tempat mencari makanan, tempat asuhan dan tumbuh besar serta tempat pemijahan bagi berbagai biota laut. Nilai ekonomis terumbu karang yang menonjol adalah sebagai tempat penangkapan berbagai jenis biota laut konsumsi dan berbagai jenis ikan hias, bahan konstruksi dan perhiasan, bahan baku farmasi dan sebagai daerah wisata serta rekreasi yang menarik.

Terumbu karang Pulau Bintan terlihat di sepanjang pesisir mulai Pesisir Tanjungpinang, Bintan Timur, Gunung Kijang, Teluk Sebong, Bintan Selatan dan pulau-pulau kecil disekitarnya. Kondisi terumbu karang di Pulau Bintan berada dalam kategori buruk sampai sedang. Tutupan karang hidup pada beberapa lokasi bervariasi, diantaranya di perairan Pantai Trikora tutupan karang hidup berkisar 5 - 61,90\% dengan rerata persentase tutupan karang hidup 25,27\%, Pulau Gyn dan Pulau Numbing tutupan karang hidup berkisar $5-42,11 \%$ dengan rerata tutupan karang hidup 21,88\% (LIPI, 2009).

Penyebab kerusakan ekosistem terumbu karang adalah akibat sedimentasi dari aktivitas pembukaan lahan, penangkapan ikan dengan cara destruktif (bahan peledak dan sianida, dan bubu), 
pencermaran (dari pertambangan, domestik, hotel dan restoran), pariwisata bahari (penyelaman, penambatan kapal) dan pengambilan batu karang untuk bangunan. Pada periode tahun 2008 - 2009 masih ditemukan penurunan persentase tutupan karang hidup pada beberapa titik pemantauan (LIPI, 2009). Lokasi yang mengalami penurunan persentase tutupan karang hidup adalah di Desa Malang Rapat dari 17,5\% menjadi 16,35\%, Desa Teluk Bakau dari 59,6\% menjadi 52,8\% dan Desa Kawal dari 42,19\% menjadi 36,8\%. Penurunan tutupan karang hidup ini diduga akibat penebangan hutan dan perubahan tata guna lahan yang menyebabkan peningkatan sedimentasi (Sudiono, 2008) serta dipicu oleh kekeruhan dan sedimentasi dari kegiatan penambangan bauksit, granit dan pasir darat.

\section{Pengaruh Daya Dukung Fungsi Lindung Terhadap Pembangunan Wilayah}

Penurunan daya dukung fungsi lindung dibeberapa wilayah Pulau Bintan akan berpengaruh terhadap Pembangunan wilayah. Dampak yang mungkin akan ditimbulkannya adalah

\section{Krisis sumber daya air}

Jumlah penduduk yang besar dan alih fungsi kawasan lindung sebagai Catchmet Area menjadi permukiman, perkebunan dan pertambangan menyebabkan krisis sumberdaya air. Kekurangan air ini tidak bisa dicukupi oleh wilayah sendiri, sehingga harus dapat pasokan dari wilayah lain di sekitarnya.

\section{Rawan pencemaran air tanah}

Tekanan penduduk dan permukiman yang padat menyebabkan kualitas air dari waktu ke waktu semakin menurun. Aktivitas manusia dan pembangunan menimbulkan limbah padat dan cair. Limbah ini berpotensi mencemari air tanah.

\section{Krisis sumber daya pangan}

Wilayah perkotaan yang sangat didominasi permukiman dan perkantoran menyebabkan ketersediaan lahan untuk memproduksi bahan pangan menjadi berkurang. Kekurangan ini bisa diatasi dengan mengimpor kebutuhan pangan dari luar kota.

\section{Rawan bencana alam}

Bencana alam yang mungkin bisa terjadi adalah kekeringan di musim kemarau dan banjir dibeberapa lokasi di Kota Tanjungpinang. Fenomena banjir yang terjadi karena drainase yang buruk serta minimnya resapan air ke tanah akibat alih fungsi lahan menjadi permukiman dan perkantoran. 


\section{Munculnya kerawanan sosial dan kriminalitas}

Kerusakan lingkungan perkotaan dengan kepadatan penduduk tinggi bisa memicu konflikkonflik sosial di masa mendatang. Konflik sosial ini secara berantai juga bisa berdampak akan semakin meningkatnya tindak kriminalitas.

\section{KESIMPULAN}

Pulau Bintan mempunyai potensi sumber daya alam yang besar dan lokasi sangat strategis terletak di Semenanjung Selatan Malaysia dan menjadi pintu gerbang Selat Malaka. Keunggulan Pulau Bintan ini memicu eksploitasi sumber daya alam secara berlebihan dan pembangunan wilayah yang tidak mengindahkan kelestarian lingkungan.

Analisis daya dukung fungsi lindung tingkat regional menunjukkan kondisi daya dukung fungsi lindung Pulau Bintan berada dalam kondisi sedang. Daya dukung fungsi lindung di Pulau Bintan ini tidak merata. Kota Tanjungpinang secara umum daya dukung fungsi lindungnya sudah rusak sedangkan Kabupaten Bintan masih dalam kondisi baik. Kerusakan lingkungan di Kota Tanjungpinang disebabkan oleh perkembangan kota yang pesat dengan maraknya alih fungsi kawasan lindung menjadi permukiman dan perkantoran.

Analisis daya dukung fungsi lindung tingkat sektoral ditunjukkan beberapa kawasan lindung di Pulau Bintan sudah dalam kondisi rusak. Kawasan hutan lindung yang rusak terdapat di Hutan Lindung Sungai Pulai, Hutan Lindung Bukit Lengkuas, Hutan Lindung Gunung Kijang dan Hutan Lindung Sei Jago. Kawasan hutan mangrove yang rusak berada di Teluk Bintan dan Tanjung Mamboi sedangkan terumbu karang yang rusak berada di Pantai Trikora, Pulau Gyn, Pulau

Numbing dan Desa Malang Rapat. Kerusakan di kawasan lindung ini diakibatkan oleh illegal logging, penambangan bauksit, sedimentasi dan pemanfaatan lahan untuk perkebunan sawit, kebun karet rakyat, permukiman dan pariwisata. 


\section{DAFTAR PUSTAKA}

Adriman, Purbayanto, A., Budiharso, S., dan Damar, A. 2012. Analisis Keberlanjutan Pengelolaan Ekosistem Terumbu Karang Di Kawasan Konservasi Laut Daerah Bintan Timur Kepulauan Riau. Jurnal Perikanan dan Kelautan 17,1 (2012) : 1-15.

BAPEDA Propinsi Kepulauan Riau. 2006. Rencana Pembangunan Jangka Panjang Propinsi Kepulauan Riau Tahun 2006 - 2018. Kepulauan Riau.

BAPEDA Propinsi Kepulauan Riau. 2008. Rencana Tata Ruang Wilayah Propinsi Kepulauan Riau. Kepulauan Riau.

BPS Propinsi Kepulauan Riau. 2009. Provinsi Kepulauan Riau Dalam Angka Tahun 2008. Kepulauan Riau.

BPS Propinsi Kepulauan Riau. 2010. Provinsi Kepulauan Riau Dalam Angka Tahun 2009. Kepulauan Riau

BPN Kabupaten Bintan. 2010. Informasi Pertanahan Kabupaten Bintan Tahun 2010. Bintan.

BPN Kota Tanjungpinang. 2011. Informasi Pertanahan Kota Tanjungpinang Tahun 2011. Tanjungpinang .

LIPI. 2009. Data Dasar Aspek Sosial Terumbu Karang Indonesia Untuk Pulau Bintan. Coremap II. Jakarta.

Deputi Bidang Tata Lingkungan KLH. 2010. Pedoman Penggunaan Kriteria dan Standar untuk Aplikasi Daya Dukung dan Daya Tampung Lingkungan Hidup dalam Pengendalian Perkembangan Kawasan. Kementrian Lingkungan Hidup. Jakarta.

Muta'ali, L. 2012. Daya Dukung Lingkungan Untuk Perencanaan Pengembangan Wilayah. Badan Penerbit Fakultas Geografi (BPFG). Yogyakarta.

Muta'ali, L. 2003. Studi Penentuan Desa-Desa Pusat Pertumbuhan Di Propinsi DIY. Majalah Geografi Indonesia. 17 (I). Yogyakarta.

Sudiono, G. 2008. Analisis Pengelolaan Terumbu Karang Pada Kawasan Konservasi Laut Daerah (Kkld) Pulau Randayan Dan Sekitarnya Kabupaten Bengkayang Provinsi Kalimantan Barat. Tesis. Universitas Diponegoro. 